\title{
Women and Urinary Tract Infection
}

\section{R Nambu Mahalakshmi* and R Thillai Raj Kumar}

Department of Medical Laboratory Technology, Raja College of Arts and Science, Raja Nagar, Kunjarvalasai, Tamil Nadu, India

*Corresponding Author: R Nambu Mahalakshmi, Department of Medical

Laboratory Technology, Raja College of Arts and Science, Raja Nagar, Kunjarvalasai, Tamil Nadu, India.
Received: June 21, 2021

Published: July 19, 2021

(C) All rights are reserved by $\mathbf{R}$ Nambu

Mahalakshmi and R Thillai Raj Kumar.

\begin{abstract}
Women face health problems in day to day life. One of the serious issues is urinary tract infection. Urinary infection is very common, but women get more infection than men. UTI caused by the organisms cause serious urinary inflammation. The major causative organisms are E. coli, Pseudomonas aeruginosa, Staphylococcus aureus, Enterococcus faecalis etc. Today, all age group of women have urinary infection. Women can get easily infection than men through improper hygiene, sexual activity, maternal time, menstrual cycle, and menopause. In this study, frequently we found that those having above 40 age group women have got more infection with E. coli and Pseudomonas aeruginosa. Few peoples were infected by mold. In this primary investigation, we isolated clinical pathogens from normal urine samples by plate count method. In macroscopic observation we found cloudiness or turbidity, also we performed basic tests like glucose, ketone bodies, nitrite, bile deposits etc. In microscopic studies, like WBCs, RBCs, Epithelial cells, Hyaline cast, Waxy cast. Next, the studies focus on antimicrobial susceptibility test.
\end{abstract}

Keywords: Antimicrobial; Urinary Infection; Bile; Ketone Bodies; Clinical Pathogens

\section{Introduction}

Urinary tract infection (UTI) is the second most common clinical indication for empirical antimicrobial treatment in primary and secondary care, and urine samples constitute the largest single category of specimens examined in most medical microbiological laboratories. Healthcare practitioners regularly have to make decisions about prescription of antibiotics for UTI. Criteria for the diagnosis of UTI vary greatly, depending on the patient and the context [1].

UTIs refer to the presence of microbial pathogens within the urinary tract and it is usually classified by the site of infection as bladder (cystitis), kidney (pyelonephritis) or urine (bacteriuria). They are asymptomatic or symptomatic. UTIs that occur in a nor- mal genitourinary tract with no prior instrumentation are considered as "uncomplicated", whereas "complicated" infections are diagnosed in genitourinary tracts that have structural or functional abnormalities including instrumentation such as indwelling urethral catheters, and are frequently asymptomatic [2,3].

UTIs, including cystitis and pyelonephritis, are the most common infectious diseases in childhood [4]. E. coli accounts for as much as $90 \%$ of the community-acquired and $50 \%$ of the nosocomial UTIs [5]. UTIs are responsible for more than 7 million patient visits and one million hospital admissions (due to complications) per year in the United States only. Additional diseases include neonatal meningitis responsible for about 0.25 per 1000 live births in industrialized countries and 2.66 per 1000 in developing countries [6]. 
In the United States, $70-80 \%$ of complicated UTIs are attributable to indwelling catheters [7], accounting for 1 million cases per year [4]. Catheter associated UTIs (CAUTIs) are associated with increased morbidity and mortality and are collectively the most common cause of secondary bloodstream infections. Risk factors for developing a CAUTI include prolonged catheterization, female gender, older age and diabetes [8].

The proliferation of bacteria in the urothelium can be asymptomatic or symptomatic, which causes inflammatory response and symptomatic case characterized by a wide range of symptoms including, fever, lethargy, anorexia and vomiting [9-14].

However, both genders are susceptible to this type of infection, but women are more, as their reproductive anatomy and physiology are more sensitive. Half of all women by 32 years age had experienced at least an infection history.

Normally, urinary tract urine mostly dominated by E. coli $75 \%$ - 80\%, followed by S. saprophyticus 10 - 15\%. While, Anatomy or physiological factors cause abnormality of urinary tract and lead to localize infectious bacteria, such as different species of Klebsiella, Proteus, Enterobacter, Enterococcus, Staphylococcus and Pseudomonas aeruginosa. Those bacteria are more common in most of the cases, and infrequently cause to uncomplicated cystitis and pyelonephritis.

While, Anatomy or physiological factors cause abnormality of urinary tract and lead to localize infectious bacteria, such as different species of Klebsiella, Proteus, Enterobacter, Enterococcus, Staphylococcus and Pseudomonas aeruginosa. Those bacteria are more common in most of the cases, and infrequently cause to uncomplicated cystitis and pyelonephritis [15-20].

Bacterial identification and susceptibility tests are important for selecting the appropriate antimicrobial agent affecting bacterial diseases [21]. Thus, the accurate diagnosis of UTI and determination of antibiotic sensitivity pattern is important for selection of appropriate drug for effective treatment. This is why this study is important worldwide. Despite published guidelines for the optimal selection of an antimicrobial agent and duration of therapy, studies demonstrate a wide variation in prescribing practices. The present study focus on how does a woman infected with uropathogenic problems.

\section{Materials and Methods}

\section{Sample collection}

We asked patients to clean their genital area, totally we collected 11 from women. The midstream urine samples were collected in sterile container and immediately subjected under microbiological laboratory.

\section{Parameters}

The samples were analyzed recorded the urine appearance, volume, color, $\mathrm{pH}$, odour, sediment.

\section{Culturing and identification}

Serial dilution agar plating method

This method is used to isolation of bacteria and enumeration of presence of microorganisms. The basic serial dilution procedure was followed (Dubey and Maheswari) to isolate the bacteria, the basic media were used Mac Conkey agar, and here midstream urine samples were used. A specimen was considered positive for UTI if a single organism was cultured at a concentration of $>10^{5} \mathrm{cfu} / \mathrm{ml}$, or when a single/organism was cultured at a concentration of $10^{4}$ $\mathrm{cfu} / \mathrm{ml}$ while $>5$ leukocytes per high-power field were observed on microscopic examination of the urine.

\section{Urine examination}

Gram staining procedure was performed to identify the colony morphology, deposits, blood cells also recorded. The following tests were performed, ketone bodies, bile pigment, bile salt, glucose, nitrite.

\section{Results and Discussions}

Urine samples of 11 were collected from all age group of women, three of them above 40. In this study, frequently we isolated $E$. coli and Pseudomonas aeruginosa. The urine samples were collected periodically and recorded. We observed that above 40 age group of women highly risk with $E$. coli and P. aeruginosa also containing pus cells. Urine parameters were measured like $\mathrm{pH}$, odour, volume, appearance, colour, deposits for different age group of women (Table 1). The midstream urine samples were cultured on Mac Conkey agar medium (Table 2). The selected colonies were stained with gram staining procedure. Based on microscopic analysis we recorded pus cells, RBCs, Epithelial cells, deposits like hyaline cells, urobilinogen phosphate deposition. 


\begin{tabular}{|c|c|c|c|c|c|c|c|c|c|}
\hline $\begin{array}{c}\text { Test } \\
\text { sample }\end{array}$ & Age & Gender & $\begin{array}{c}\text { Colour of the } \\
\text { urine }\end{array}$ & Appearance & pH & Pus cells & Volume & Ketone & Urobilinogen \\
\hline 1 & 38 & F & Pale yellow & Turbidity & Acidic & $\begin{array}{c}\text { Packed with } \\
\text { pus cells/ hpf }\end{array}$ & 30 & None & -ve \\
\hline 2 & 50 & F & Pale yellow & Turbidity & Acidic & $\begin{array}{c}\text { Packed with } \\
\text { pus cells/ hpf }\end{array}$ & 30 & None & +ve \\
\hline 3 & 25 & M & Yellow & Clear & Acidic & Nil & 30 & None & -ve \\
\hline 4 & 29 & F & Pale yellow & Turbidity & Acidic & Nil & 30 & None & -ve \\
\hline 5 & 25 & F & Dark Yellow & Clear & Acidic & Nil & 30 & None & -ve \\
\hline 6 & 24 & F & Yellow & Clear & Acidic & Nil & 30 & None & -ve \\
\hline 7 & 38 & F & Yellow & Turbidity & Acidic & Packed with & 30 & -ve \\
\hline 8 & 26 & F & Dark Yellow & Turbidity & Acidic & Nil & 30 & None & -ve \\
\hline 9 & 19 & F & Yellow & Clear & Acidic & Nil & 30 & None & -ve \\
\hline 10 & 19 & F & Yellow & Clear & Acidic & Nil & 30 & None & -ve \\
\hline 11 & 18 & F & Yellow & Clear & Acidic & Nil & 30 & None & -ve \\
\hline
\end{tabular}

Table 1: Parameters of urine samples.

\begin{tabular}{|c|c|c|}
\hline $\begin{array}{c}\text { Test } \\
\text { sample }\end{array}$ & Isolated bacteria & No. of colonies \\
\hline \multirow[t]{2}{*}{1} & E. coli & 4 \\
\hline & P. aeruginosa & 3 \\
\hline \multirow[t]{2}{*}{2} & E. coli & 5 \\
\hline & P. aeruginosa & 5 \\
\hline \multirow[t]{2}{*}{3} & E. coli & 0 \\
\hline & P. aeruginosa & 0 \\
\hline \multirow[t]{2}{*}{4} & E. coli & 2 \\
\hline & P. aeruginosa & 1 \\
\hline \multirow[t]{2}{*}{5} & E. coli & 3 \\
\hline & P. aeruginosa & 2 \\
\hline \multirow[t]{2}{*}{6} & E. coli & 1 \\
\hline & P. aeruginosa & 1 \\
\hline \multirow[t]{2}{*}{7} & E. coli & 2 \\
\hline & P. aeruginosa & 1 \\
\hline \multirow[t]{2}{*}{8} & E. coli & 3 \\
\hline & P. aeruginosa & 2 \\
\hline \multirow[t]{2}{*}{9} & E. coli & 2 \\
\hline & P. aeruginosa & 1 \\
\hline \multirow[t]{2}{*}{10} & E. coli & 2 \\
\hline & P. aeruginosa & 1 \\
\hline \multirow[t]{2}{*}{11} & E. coli & 2 \\
\hline & P. aeruginosa & 1 \\
\hline
\end{tabular}

In this present study, we monitor the frequent report for the persons. Depend upon the personal hygienic habit, proper sanitation etc., may create the infection again and again. Antibiotics treatment will give better results. The future scope of this study, will be analyze the patient's abnormalities with UTI and antimicrobial susceptible also compare the urinary inflammation for men and women.

\section{Conclusion}

In this juncture, E. coli infection was very common for women. We proceeded 11 samples out of 10 were infected both $E$. coli and $P$. aeruginosa. The parameters of the samples were clearly understood. In future studies focus on antibiotic assay, comparative analysis, along with uropathogenic infections.

\section{Bibliography}

1. Shill MC., et al. "Prevalence of Uropathogens in Diabetic Patients and Their Corresponding Resistance Pattern: Results of a Survey Conducted at Diagnostic Centers in Dhaka, Bangladesh". Oman Medical Journal 25 (2010): 282-285.

2. Gonzalez CM and Schaeffer AJ. "Treatment of urinary tract infection: what's old, what's new and what works". World Journal of Urology 17 (1999): 372-382.

Table 2: Isolated bacteria of urine samples. 
3. Stamm WE and Hooton TM. "Management of urinary tract infections in adults". The New England Journal of Medicine 329 (1993): 1328-1334.

4. Robinson JL., et al. "Infectious Diseases and Immunization Committee". Paediatrics and Child Health 19 (2014): 315-319.

5. Vila J., et al. "Are Quinolone-Resistant Uropathogenic Eschericia coli Less Virulent?" The Journal of Infectious Diseases 186 (2002): 1039-1042.

6. Ron EZ. "Distribution and Evolution of Virulence Factors in Septicemic Eschericia coli". International Journal of Medical Microbiology 300 (2010): 367-370.

7. Lo E., et al. "Strategies to prevent catheter-associated urinary tract infections in acute care hospitals: 2014 update". Infection Control and Hospital Epidemiology 35 (2014): :464-479.

8. Chenoweth CE., et al. "Diagnosis, management, and prevention of catheter-associated urinary tract infections". Infectious Disease Clinics of North America 28 (2014): 105-119.

9. Onu GA., et al. "Isolation, identification and characterization of urinary tract infections bacteria and the effect of different antibiotics". Journal of Natural Sciences Research 3 (2013): : 150-159.

10. Gonzalez CM and Schaeffer AJ. "Treatment of urinary tract infection: What's old, what's new, and what works". World Journal of Urology 17 (1999): 372-382.

11. Liang FX., et al. "Cellular basis of urothelial squamous metaplasia roles of lineage heterogeneity and cell replacement". Journal of Cell Biology 171 (2005): : 835-844.

12. Foxman B. "Epidemiology of urinary tract infections: Incidence, morbidity, and economic costs". American Journal of Medicine (2003): 113.

13. Weichhart T., et al. "Current concepts of molecular defence mechanisms operative during urinary tract infection". European Journal of Clinical Investigation 38 (2008): : 29-38.

14. Williams G and Craig JC. "Long-term antibiotics for preventing recurrent urinary tract infection in children". Cochrane Library: Cochrane Reviews 16.3 (2011).
15. Balakrishnan Hill V. "Dealing with urinary tract infections". The Pharmaceutical Journal 287 (2010): 687-690.

16. Ronald A. "The etiology of urinary tract infection: Traditional and emerging pathogens". Dis Mon 49 (2003): : 71-82.

17. Stamm WE and Hooton TM. "Management of urinary tract infections in adults". The New England Journal of Medicine 329 (1993): 1328-1334.

18. Kibret $\mathrm{M}$ and Abera B. "Prevalence and antibiogram of bacterial isolates from urinary tract infections at dessie health research laboratory, Ethiopia". Asian Pacific Journal of Tropical Biomedicine 4 (2014): : 164-168.

19. Farajnia S., et al. "Causative agents and antimicrobial susceptibilities of urinary tract infections in the northwest of Iran". International Journal of Infectious Diseases 13 (2009): :140-144.

20. Hooton TM. "Practice guidelines for urinary tract infection in the era of managed care". International Journal of Antimicrobial Agents 11 (1999): 241-245.

21. Gentilini E., et al. "Antimicrobial Susceptibility of CoagulaseNegative Staphylococci Isolated from Bovine Mastitis in Argentina”. Journal of Dairy Science 85 (2002): 1913-1917.

22. Hooton T., et al. "International Clinical Practice Guidelines for the Treatment of Acute Uncomplicated Cystitis and Pyelonephritis in Women: A 2010 Update by the Infectious Diseases Society of America and the European Society for Microbiology and Infectious Diseases". Urinary Catheter Guidelines•CID Clinical Infectious Diseases 50 (2010): 625.

23. Gupta K., et al. "International Clinical Practice Guidelines for the Treatment of Acute Uncomplicated Cystitis and Pyelonephritis in Women: A 2010 Update by the Infectious Diseases Society of America and the European Society for Microbiology and Infectious Diseases". Clinical Practice Guidelines•CID 52 (2011): 103.

24. Abbo LM and Hooton TM. "Antimicrobial Stewardship and Urinary Tract Infections". Antibiotics 3 (2014): 174-192.

25. Grabe M., et al. "Guidelines on Urological Infections”. European Association of Urology, Arnhem (2013). 
26. Spoorenberg V., et al. "Appropriate Antibiotic Use for Patients with Complicated urinary Tract Infections in 38 Dutch Hospital Departments: A Retrospective Study of Variation and Determinants". BMC Infectious Diseases 15 (2015): 505.

27. Schneider PF and Riley TV. "Staphylococcus saprophyticus urinary tract infections: Epidemiological data from Western Australia". European Journal of Epidemiology 12 (1996): 51-54.

Volume 3 Issue 8 August 2021

(C) All rights are reserved by R Nambu Mahalakshmi and R Thillai Raj Kumar. 